\title{
An Effective Supervisory Model to Help MA English Students in the Process of Writing Their Thesis
}

\author{
Hamid Rahmani Sangani (Corresponding author) \\ Department of English Language, Velayat University of Iranshahr, Iran \\ E-mail: h_rahmani_s@yahoo.com \\ Seyed Iman Bassir \\ Department of English Language, Velayat University of Iranshahr, Iran \\ E-mail: imanbassir@yahoo.com \\ Latifah Jalali \\ Department of English Language, Velayat University of Iranshahr, Iran \\ E-mail: L.Jalali@velayat.ac.ir
}

Received: 09-06-2016

Published: 02-01-2017
Accepted: 18-08-2016

doi:10.7575/aiac.ijalel.v.6n.1p.11
Advance Access Published: November 2016

URL: http://dx.doi.org/10.7575/aiac.ijalel.v.6n.1p.11

\begin{abstract}
Conducting a research project and writing up a thesis could be as nearly demanding as it is essential for MA students to achieve their academic goals, particularly in developing world contexts such as Iran. One main reason for this, as experienced by some of the students, is the insufficient and inefficient guidance which the students receive from their supervisors. Meanwhile, the initial review of the available documents and syllabi in our context, Iran, demonstrated that there are no transparent comprehensive guidelines recommended for the supervisor-student relationships. In order to respond to these challenges, a multiple-case study, including four cases, was designed. Each of the four cases consisted of one MA TEFL student who was guided by a supervisory team including two of the three supervisors. The team members held their consulting sessions for each student individually. Each of the students' activities and interactions were considered and reflected on regularly by the supervisory team in order to explore the challenges the students and their supervisors encountered and then to propose responses to them. The students were regularly interviewed about the efficiency of the whole process of the supervision, particularly the suggested responses and changes, to detect its successes and failures. An ongoing thematic analysis was used to analyse the collected data. The process helped the researchers, who were also the participants, to develop a supervisory model which hopefully facilitates the process of writing an MA thesis. The findings could be immensely helpful for the syllabus designers and supervisory teams as well as MA and PhD students.
\end{abstract}

Keywords: Supervisor-Student Relationship, Supervisory Model, EL Students, MA Research, Thesis Writing

\section{Introduction}

One of the most challenging tasks every MA or PhD student has to tackle in the course of her/his academic education is writing a thesis. This problem is especially serious in developing world contexts such as Iran, where the system of education is not research-based, and MA thesis is probably the first serious research work done by the students. Another factor that makes the problem even more serious, as experienced by some of the students, is the insufficient and inefficient guidance which the students receive from their supervisors. A large number of supervisors in these contexts do not seem to have adequate theoretical knowledge about the principles and methodology of research. Moreover, due to the nonexistence of clear rules about the duties of supervisors and the absence of sufficient control of the authorities, in many cases even this inadequate knowledge fails to be transferred to the students. The present study was carried out in order to explore the challenges of the supervisor-student relationship and find responses to these challenges in a context in Iran. Taking into consideration the importance of the supervisors' engagement in and their control of the students' research process, as highlighted by de Kleijn, Mainhard, Meijer, Pilot, and Brekelmans (2011) and de Kleijn, Meijer, Pilot, and Brekelmans (2014), the present study aims at suggesting an effective model of supervision to be adopted for MA students. It is hoped that through the application of this model, the process of writing the thesis becomes easier and more pleasant for the students.

The paper starts with a brief review of the available literature to locate the study and raise its focus. After that the methodology is discussed. The findings of the study and the model developed for an effective teacher-student relationship are presented next. The paper ends with some ending remarks in the conclusion. 


\section{Review of the Literature}

Numerous studies have already been published on the importance of supervision and the nature of the relationship between supervisors and their graduate or postgraduate students. In a case study, Dysthe, Samara, and Westrheim (2006) investigated the effectiveness of a model employed to promote the process of the supervision of the students' research. In their model, the students are supervised by a group of supervisors as well as an individual one. Besides, the students participate in student meetings to share and discuss their challenges and ideas. Such a "three-pronged approach" was found effective, as the students could improve their thinking and communicative skills.

In another case study, Azman, Mohd Nor, Mohd Nor, and Aghwela (2014) investigated the impact of the feedback international doctoral students receive from their supervisors on their thesis development. They commented that effective feedback should fulfill the four major roles of supervision: the advisory role, the quality control role, the nurturing supportive relationship role, and the coacher (or guidance) role. The results of their study showed that a mixture of written and face-to-face feedback would be the most effective mode. Furthermore, feedback which only poses unclear and general questions such as "What do you mean?" or mere question marks should be supplanted by more clear and directive feedback.

Styles and Radloff (2001) introduced a synergistic model of supervision for PhD students which is "characterized by complementarity of supervisor and student roles at different stages, and by substantial positive learning outcomes for both supervisor and student" (pp. 98-99). Being a supervisor and supervisee working on the same project themselves, the two authors of this article consider a sound supervisory relationship as the most vital factor for the success of a research process. They believe that a thesis does not belong just to a student; it belongs to her/his supervisor as much. Both the supervisor and the supervisee increase their knowledge and skills through working on the thesis, as evidenced by the first author's admission in one part of the article: "I am convinced I have gained as much and more than Alex [the second author, i.e. the supervisee]" (p. 104).

Based on the two factors of structure and support, Gatfield (2005) enumerated four supervision styles: laissez-faire style (low structure; low support), pastoral style (low structure; high support), directorial style (high structure; low support), and contractual style (high structure; high support). None of these styles is intrinsically good or bad; it is "the candidate's attitudes and responses" (p. 318) which determine the preferred style. Since these attitudes and responses change during the different stages of the composition of the thesis, teachers should also change their supervision style "when the situation demands" (p. 322).

In their case study, Sidhu, Kaur, Fook, and Yunus (2014) compared and contrasted postgraduate supervision practices from the perspectives of doctoral students studying in Malaysia and the United Kingdom. The results of the study showed that these two groups of students had different ideas about the roles and responsibilities of supervisors. While Malaysian supervisees, for the most part, focused on the personality factors, expecting their supervisors to give them motivation and boost their confidence and morale, respondents from the UK laid most of their emphasis on the knowledge and academic expertise of their supervisors. Malaysian students were also more dependent on their supervisors and had higher expectations of them.

Lindén (1999), on the basis of her assumption that "narratives have considerable potential to sensitize supervisors to aspects of their role, and hence to enhance the quality of their supervision" (p. 351), asked 444 supervisors to write narratives based on their recollection of some problems they had faced in their academic life either as supervisors or $\mathrm{PhD}$ students. The analysis of these narratives showed that different factors related to the $\mathrm{PhD}$ students, the supervisors, the situation, the organization, and the task were perceived by the writers of the narratives to be the main causes of these problems.

In another study, Cullen, Pearson, Saha, and Spear (1994) have reviewed the PhD students' ideas about the way they have been supervised and the supervisors' ideas about the way they supervise their $\mathrm{PhD}$ students. They emphasize that supervisors should go beyond routines by reflecting back on their practice in order to effect a change and develop. Supervisors need institutional support and encouragement in order to adopt such a reflective approach (p. 112). Furthermore, "the overall effectiveness of the total supervision received by" postgraduate students should be evaluated by the authorities (p. 113).

What is emphasized by most of the studies listed above is the supervisors' influential role in helping their students conduct their theses more effectively.

\section{Statement of the Problem}

In our context, a university in Iran, the observed supervision styles mostly resemble to the 'Laissez-faire style' (Gatfield, 2005, p. 317). The supervisory meetings are not very organized because the supervisors are not encouraged to abide by certain regulations set by the authorities. The MA students do not seem inspired and supported to conduct their research effectively. This might be related to unmonitored, one-by-one supervisor-student relationship which has been emphasized by some researchers (Zuber-Skerrit \& Ryan, 1994; Burgess, 1994; Delamont, Parry, \& Atkinson, 1998; Lee \& Green, 1998; Yeatman, 1995; Deem \& Brehony, 2000).

Sidhu et al. (2014) found that in non-Western contexts, postgraduate students are dependent on their supervisors. They suggest that a model be developed to increase students' autonomy. On the other hand, in developing contexts such as Iran, it has been experienced that students are not only dependent on their supervisors, but also used to uncritically copying other scholars' content and structures. This is what has been noticed repeatedly by the researcehrs and their 
colleagues in their students' papers. Therefore, there was a need to investigate the challenges in the supervisor-student relationship in the given context in order to help the students develop and become more qualified independent researchers.

\section{Methodology}

A qualitative research method was employed to achieve the aims of the study and to respond to the research questions. Four groups were made to construct a multiple-case study. Each of the four cases consisted of one MA TEFL student who was guided by a supervisory team, including two supervisors.

\subsection{Participants}

The main population of the study consisted of four students of Velayat University of Iranshahr who worked on their MA thesis, two male and two female students, and three faculty members of the English department of the university who formed the advisory team. The students, aged between 23 and 25, were the only MA students who had completed their theoretical course and were assigned randomly to four groups under the supervision of the same first supervisor and two second supervisors. The supervisors had been appointed by the English department of Velayat University. The first supervisor was older and more experienced, having already supervised more than 14 MA theses and refereed a lot of MA these in various universities. The second supervisors, however, were rather young and this was their first experience of supervision. All of them were collaborative and interested in self-development. While each and every member of the supervisory team had the overall responsibility of staying updated and involved in all the students' conditions, especially through close collaboration with their colleagues, one was specified as the supervisor and each of the other two members was decided to work exclusively and specifically as the advisor of two certain students.

\subsection{Methods of the Data Collection}

Eight consulting sessions were held by the team members for each student individually. Each of the students' activities and interactions were considered and reflected on regularly by the supervisory team in order to explore the challenges the students and their supervisors encountered and then to propose responses to them. In addition, all the participants kept a journal writing their feedback. Four group discussions were held after every two consulting sessions to let the members share their concerns and progress. The students were also regularly interviewed after the sessions about their experience of being supervised and what individual support or skill they might need. This would give an opportunity to investigate the efficiency of the supervisor-student relationship and detect the successes and failures of the whole process which took four months.

\subsection{Purpose and Research Questions}

The current study was designed to investigate the supervisor-student relationships in a particular context in Iran and also to develop a supervisory model to respond to the existing and probable challenges.

The following research questions guided the study:

1. How do the supervisory meetings work?

2. How are the supervisory meetings run?

3. What can be done by the supervisors to have better supervisions?

Answers to the research questions will be provided by developing a model at the end.

\section{4 Procedure}

The three supervisors, as committed teachers, decided to work as researchers in their context, hoping to develop and improve their practice. To do so, the supervisory teams were formed and the study started.

First, a preliminary study was carried out to explore the current procedure of supervision in the postgraduate Iranian programs. A series of unstructured oral interviews with ten teachers from English departments were conducted and reported to the research team in May, 2015. The interviewees had either ongoing supervisory experience with MA students or fresh memories of being supervised during their own postgraduate studies. The interviews had mostly focused on the interrelation between the supervisors and supervisees, their expectations of each other, points of misunderstanding and disappointment, the beneficial phases, and also the suggestions and ideas of the interviewees themselves. Afterward the team focused on the available documents concerning rules and regulations of supervision and got surprised to find the least guidelines for both supervisors and supervisees in their context, i.e. Iran.

After the above-mentioned enquiry, the supervisory team held their eight consulting sessions every two weeks. All the members were asked to write a report about their observation of each session. After each session, the students were also interviewed. This would give a chance to triangulate the data by confirming the reports and to collect more information. The results of the individual sessions and interviews were discussed at the end of every month in four group gatherings. The supervisors' observations of these meetings were also written and recorded as the data base. The researchers' own reports as well as the students' ones were analysed and the findings were used in order to develop a model at the end.

\section{Analysis, Findings, and Discussions}

In this qualitative study, an ongoing thematic analysis was done during the data collection. The data collected through reports and interviews were regularly explored by the researches in order to understand the participants' concerns and challenges about supervising and being supervised. The results of each meeting were used by the researchers to improve the supervisor-student relationship in the following meetings; the procedure adopted was very similar to action research 
(Edge, 2001). The project was not a mere observation of the ongoing process and reflecting on the mechanism. It also involved practical intervention of the advisory team by making some changes based on their reflection in order to supervise their students' activates more efficiently. In other words, like action research, the supervisors followed a reflection-plan-change procedure to help their students learn how to research.

The findings, as themes which emerged from the data, are as follows:

\subsection{Supervisors' Responsibility and Engagement in the Research Process}

뀔 upervisors' involvement with their students' research process and their close observation of the research process seem vital in helping students conduct an effective enquiry. Being responsible, the supervisors read their students' reports and listened to their challenges in order to give them some feedback. There is evidence in the data that demonstrates the supervisors' reaction to the students' ambiguity. For example,

A supervisor: I couldn't understand her [the student's] methodology and the research question and the anticipated result. In other words, I didn't understand what the research is going to prove and what approach or methodology she is going to adopt. I hope that in the next sessions or after reading her proposal, these mysteries will be solved for me.

On the one hand, the extract shows the supervisor's feedback which could make the students think and understand their research better. On the other hand, it shows that the supervisors got engaged in the research process from the beginning. A reflection on such extracts indicates that supervisors should take the responsibility to discuss with their students all aspects of their research designs before they embark on doing their research.

This point is considered very important in such particular situations because it can respond to a big challenge. As it had been observed by one of the researchers, who had been the chair of an MA viva, a student's second supervisor had just received his student's thesis, and the only ones who usually read a thesis carefully before the viva are the referees. It has also been heard a lot that in such contexts some supervisors usually read and give feedback only on finished papers, i.e. as products. This is why one of the supervisors emphasized that"the students should be so thankful to have such lecturers [supervisors] that devote their valuable times to them [the students] and read all of their writing meticulously." Therefore, it can be claimed that the supervisors' commitment is of great importance in such contexts.

\subsection{Regular Meetings}

In the first general meeting, the supervisors and the students emphasized the need to meet each other regularly. One of the supervisors mentioned, in her/his journal, that "not meeting their supervisors regularly seems to be the main reason why some students cannot complete their research on time." In other words, when students do not meet their supervisors regularly, sometimes they cannot manage their time individually to follow their timetables. For this reason, the supervisors agreed to hold meetings once every two weeks.

The students' later comments showed that the regularly-held meetings were very efficient in helping them to organize their materials and activities according to their timetable. This is demonstrated in the following quotation:

A student: We have got well-organized and we stick to the deadlines set by our supervisors. It seems very difficult to do our jobs in time without being pushed forward by these sustained meetings.

This extract from the students' notes illustrates that they need to meet their supervisors regularly to be encouraged to do their assignments in the fixed times.

\subsection{Personal Development Files [PDF]}

The supervisors also came to know that the empathy between supervisors and students could be increased if both of them keep journals. This is why they decided to write personal development files. They wrote them after each meeting to share their understanding of the meeting. Based on what the students had written in their PDF's, it was obvious that sometimes they had misunderstood their supervisors. The students were also asked to write what their challenges were and what help they might need. The PDF's were submitted to the supervisors before the following meetings, and the supervisors had time to reflect on the students' struggles and challenges and suggest them some solutions in the next meeting. These reports were used later on by the supervisors to investigate the students' research progress. Writing reports and keeping journals as PDF's were hoped by the supervisors to help participants be reflective practitioners (Schön, 1983) in order to go beyond the routines and develop as researchers.

\subsection{Building a Rapport and Using a Proper Mode of Talk}

During the supervisory meetings, it was felt by the supervisors that building a rapport and using a particular mode of talk look very necessary for a successful supervisor-student relationship. Supervisors should collaborate, share their knowledge and experience, and support each other, so they need to establish a close rapport between themselves and their students. To do so, some motivating ideas and suggestions seemed necessary to be vocalized by the supervisors and the students as the following quotations demonstrate:

A supervisor:... they [the students] should be grateful and appreciate their [their supervisors'] help and guidance.

Another supervisor: The students have a great responsibility towards their advisors and should be in touch with them, and also they should know how to get benefit from them.

A student: We have to trust our supervisors if we want to progress and to complete our projects in the best way. 
It appears important to build and continue a close and friendly relationship between supervisors and students. Supervisors' commitment and students' trust are also highlighted in the extracts.

Moreover, being stimulated by Sangani and Stelma (2012), the supervisors tended to discuss the issues based on 'empathy', 'respect', and 'honesty' which are the central points of Edge's (1992, 2002) cooperative development. All participants also welcomed 'non-judgmental respect' (Edge, 1992, 2006) and decided to avoid 'disputational' talk (Mercer, 1995), which is characterized by disagreement and individualized decision-making. Such ground rules were jointly established during the first meetings, hoping that a mode of talk based on them might improve the relationship among the participants of the study.

\subsection{The Authorities' Observation/ Monitoring}

Another ground rule which was considered important by the supervisors is related to the role which ought to be ascribed to the authorities of the institutes as the following extracts represent:

A supervisor: I should say that monitoring does not exist in our university at all, and this is one of the reasons for the existing problems such as the presence of reluctant teachers who do not spend enough time preparing for their teaching or meeting their students to discuss their research needs maybe because they are not regularly monitored by the university.

Another supervisor: It's not just monitoring and controlling which should be done by the authorities, but on top of that the assiduous academic staff should be rewarded by them for working hard and improving the education of the university.

The supervisors as researchers came to know that they needed to be monitored by the authorities of the university, including the heads of the academic departments and the offices of Research and Academic Vice-chancellors. The supervisors believed when they were constantly observed by the senior officers, they would do their jobs better and more carefully, and the meetings would be more regular and fruitful. Furthermore, they administrators might decide to encourage and promote the supervisors who worked wholeheartedly. The same point has been recommended by Cullen et al. (1994) in the conclusion of their paper when they found that institutional support and encouragement could affect supervisors significantly to be reflective and develop. Both being monitored to be responsible and getting motivated to move on are considered very important and effective for the supervisory meetings to be successful.

\subsection{Training Supervisors}

In the developing contexts such as Iran, there are some practitioners in the field of education, including lecturers and supervisors, who are young and energetic with great desires to change and develop (Sangani, 2009, 2012). In the case of this study, as it has been stated before, two of the supervisors were young instructors who were acting as supervisors for the first time in their lives. A review of their PDF's shows very clearly how much they feel they have learned from their team activity. The following extract proves the justice of the above statement:

A supervisor: Before I started the supervision of these two theses, I did not have the vaguest idea about what a proper supervision ought to be. The supervision I myself had received during my graduate studies had caused me to think that a supervisor's duty is only to wait for a student to give a complete chapter - or maybe a complete thesis - to her/him, read it quickly, write a few notes and comments on it, and ask the student to make a few changes based on them, and not even check it again to see if the changes have been made. Now I know what supervision means.

Similar ideas were also mentioned by other staff members when they were casually interviewed about their supervisions. They believed that one reason for not being very successful was that they had not been well educated to improve their practice. Such studies may pave the way for the practitioners to get encouraged to rise to the challenge. In-service education can be very beneficial if it engages the practitioners in researching their context to understand their practice better and plan to "reshape" it (Schön, 1983, 1987).

\subsection{Supervisors' Concerns}

At the beginning, the younger supervisors grew some serious concerns about their students' writing and research skills. The intensity of one of the supervisor's worry is clear in the following quotation from his journal:

A supervisor: I felt enraged and frustrated when I read it [a student's first draft of the introductory section of his thesis]. I almost got sorry for accepting the responsibility of reading the MA theses. First of all, the paper practically did not have any coherence and clarity.

During private reflection sessions, the supervisors got determined to put up with unexpected strange situations. The supervisors' collaboration was found to be important in this regard, as it is shown in the following quotation:

A supervisor: I felt very exhausted and disappointed. Therefore, I called up my supervisor colleague to talk about the problem with him. He consoled me by saying that there was no need for anxiety. "Almost all of the MA students begin their papers in this way," he observed, "but after a while they overcome the problem and find their own way." Hearing these reassuring remarks, I made up my mind not to bother myself over such stuff anymore and rely on my colleagues' knowledge, experience, and patience.

They also got to know that they need to be optimistic about their students and to encourage them to work extra hard, as it is illustrated in the following quotation:

A supervisor: He [i.e. the same student whose weak writing had perturbed the young supervisor] listened to the comments patiently and accepted them.... His polite acceptance of our criticism made 
me feel much better... Later on, I found out that he was not so weak after all; True, his paper is not satisfactory, but considering the fact that it has been written in a hurry, it's not a hopelessly bad one. Anyway, I hope that I find him better and better each time he sends me a new section of his thesis.

\subsection{Socio-Cultural Condition of the Context}

In the current study it was found that socio-cultural conditions did not allow the supervisors and students to solely and continuously focus on the theses. For example, every once in a while students had to participate in some extra-curricular activities or engage themselves in matters other than their thesis. This is illustrated in the following quotations:

A student: During the last week, I was a little busy with a number of issues. First, I traveled to Meybod [a city in the central parts of Iran] for presenting my article in Islamic Azad University of Meybod branch. Coming back from Meybod, I studied for my PhD exam that would be held next week. I also worked on my thesis.

Due to attending a lot of conferences, the students did not have enough time to focus on their thesis. This was a big challenge and a cause of discouragement for the supervisors.

Another contextual challenge was the existence of long holidays during which the students almost stopped working, as evidenced by the following statement by one of the students: "Unfortunately, we did not do anything during the holiday since we were busy with Eid [New Year] issues." It seems that the students needed to be trained to manage their time during long holidays

5.9 Moving from Dependency on Copy/Paste and Their Supervisors to Independency

An observation of the students' primary writings revealed that they had used copy-and-paste a lot. Their lack of knowledge seemed to be the main reason for this. This is illustrated in the following quotation:

A student: For writing chapter one, I decided to read some introduction part of some other theses to become cognizant of the way other researchers developed this part.

In response to this, one supervisor suggested that "it is good to learn from the others, but not just copy and paste from here and there." The supervisors focused on motivating the students to have an analytical point of view toward the topics and to believe in themselves as researchers. Besides, the supervisors decided to help the students by discussing the different chapters and contents of some of the theses, written by the previous students, as models in their general meetings. Some of the students' writings were discussed, and the general procedure of thesis writing was explained to the students.

The supervisors also planned to provide students with opportunities to share their ideas and challenges in the general meetings. This seemed effective as one of the students said:

When we listened to what happened to other students and how they responded to their challenges we learn a lot. On top of that we see where they are [in the research process] we get motivated to keep space with their progress....

Students should work on their own topics individually; however, if they sometimes meet each other, share their challenges and progress, and receive collective guidance and advice, they will be motivated and inspired to carry on their studies.

Another challenge which was experienced by the supervisors was that the students appeared to be dependent on their supervisors excessively. It is implied in the following quotation:

A student: During these two days, I am worried and stressful, because I have only a vague idea about how a thesis should be developed. I need your [supervisors'] help.

A need was felt by the supervisors to have private meetings with each of them to listen to them more attentively and help them to get more independent. One of the students mentioned:

She [a supervisor] said she wanted to do her best, and she had a plan for the whole process of thesis writing. With this in mind, I came to this conclusion that while others are so interested and helpful to me and my work, I myself should do my best to be loyal.

In a private individual meeting, the supervisor reassured the student that she was well-prepared to help the student and give whatever help he may need. This encouraged the student to be stimulated to work harder and to spend more time. Individual supervisions could also provide a good opportunity for intellectual support. The supervisors could talk with their students personally and answer their questions patiently.

In addition, it was considered by the supervisors to give the students a chance to discuss their challenges and progress together in a forum. This was hoped to encourage collaboration and cooperation among the students in order to get more independent.

The aim of general supervisory meetings, individual supervisions, and students' own forums was to help the students believe in themselves and move toward independence.

\section{Summary of the Findings}

The researchers who were the supervisors in this study came to understand that they should primarily be committed and need to collaborate if they want to efficiently supervise their students' theses. They should hold regular meetings and build a rapport between themselves and their students. Some ground rules should be used to manage the meetings, and the meetings should be monitored by the authorities. Both supervisors and students should keep journals as PDF's to facilitate reflection on the issues discussed in the meetings. Supervisors should be trained how to supervise an MA 
thesis and learn to be tolerant toward their students and encourage them to get gradually independent in various stages of the process of their thesis. They should also be ready to respond to contextual challenges and particular socio-cultural conditions.

\section{Increasingly-Getting-Autonomous Model}

The researchers' reflection and speculation on the whole process of the supervision led them to develop and suggest the 'increasingly getting-autonomous model' (figure 1) as an answer to all the research questions of the study.

The model represents some guidelines for how to hold and run supervisory meetings. This model requires a group of supervisors, including the first supervisor (as the chairman) and second supervisors or readers, and MA or PhD students who are ready to collaborate. Within the first two meetings, they should set some ground rules for their meetings and discussions. Holding meetings once every two weeks and a non-judgmental talk based on respect appear essential, as the findings of the study suggest. Writing reflective notes and comments on what is discussed in each session in order to be shared by all the members as their feedback in the following session also seems effective. This forms the first stage of the process of supervision. In the second stage, the cyclical process begins. At first, all the members meet each other to discuss some general issues related to each of the students' research questions and designs. This session is followed by private meetings in which each student consults a supervisor individually in order to investigate the related issues exclusively. Following this meeting, all the members are supposed to write their understanding, challenges, comments, and/or solutions. This is called 'students' speculation and teachers' reflection' in the process. Next, the students can share their ideas and cooperate with each other in the forum which follows. Then, the students ought to let their supervisors know about their progress and challenges by dropping them e-mails. The information received by the supervisors should be investigated by them at the beginning of the next group meeting before the students arrive.

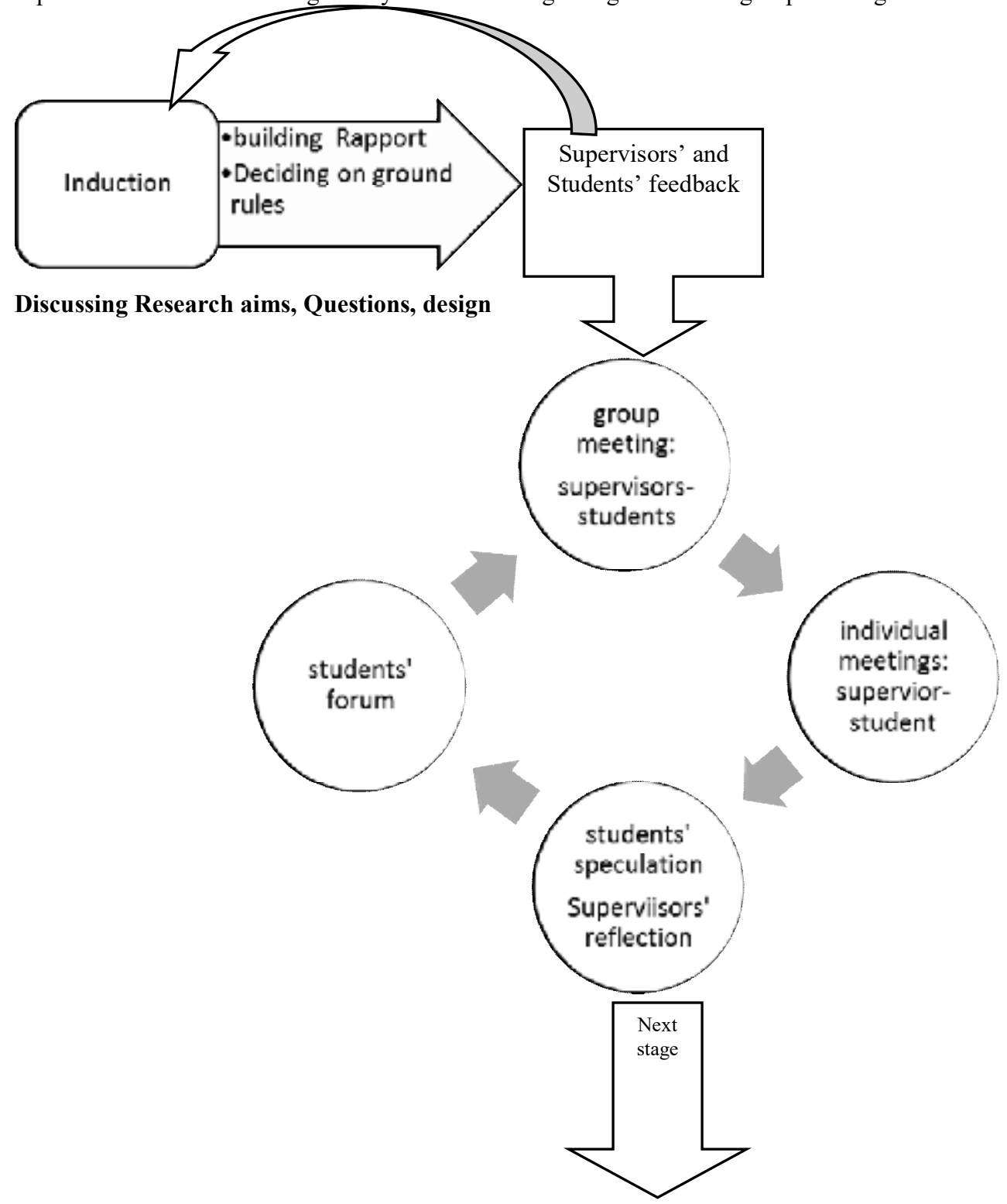

Discussing data collection and analysis

Figure 1. Increasingly-Getting-Autonomous Model 
The same process continues for all the other steps of conducting a research and writing thesis, i.e. from data collection to writing-up and viva voce. The overall aim of the model is to help students get more independent researchers. They will feel more secure and motivated when they discuss their challenges and solutions with other students and their supervisors chorally and individually and receive constructive feedback. The model seems very effective in the given context provided that the set rules are observed.

\section{Conclusion}

The fidnings of the study revealed that the supervisor-student relationships in our context needed to be improved. It was also shown that supervisors should be committed and cooperative. In an attempt to be such practitioners, we, the supervisors who participated in the study, adopting a reflective approach, explored and reflected back on our supervisory meetings, took some actions and evaluated the outcomes. This helped us to explore our role and our students' challenges which improved our understanding and led to a model along with some guidelines for the students in our context to effectively conduct a research and write up their postgraduate theses. The model aims at facilitating students' trajectory from overdependence to autonomy. This point should be considered by teachers, students and syllabus designers. For us, one conspicuous outcome of doing this research was learning while doing (Garcia, Malott, \& Brethover, 2009). It can be implied that every teacher and supervisor, in general every practitioner, can develop to do their jobs much better if they study and evaluate their context-bound practice and communicate their findings with others, e.g. by writing an article; what we managed to do by publishing this article.

Besides, the researchers recommend the Research Vice-Chancellor Offices, particularly in developing countries, to develop and adjust clear research regulations and standards, to adopt necessary measures to design and establish a strategic system in academic research activities, and to monitor the trend of their development. The Academic ViceChancellor Offices should also cooperate in exercising the research regulations as well as the evaluation and monitoring of research projects, especially through the improvement of academic services to and cooperations with researchers at the level of faculties and colleges to facilitate the development of the projects.

This study was a qualitative one and was limited to a particular context. Similar researches in other contexts are suggested to be conducted in order to contribute to the knowledge. Moreover, the model which was developed can be employed and investigated by other researchers.

\section{References}

Azman, H., Mohd Nor, N. F., Mohd Nor, N. F., \& Aghwela, H. O. M. (2014). Investigating supervisory feedback practices and their impact on international research student's thesis development: A case study. Procedia Social and Behavioral Sciences, 141, 152-159. DOI: 10.1016/j.sbspro.2014.05.028

Burgess, R. G. (Ed,) (1994). Postgraduate education and training in the social sciences: Processes and products. London: Jessica Kingsley.

Cullen, D. J., Pearson, M., Saha, L. J., \& Spear, R. H. (1994). Establishing effective PhD supervision. Canberra: Department of Employment, Education and Training, AGPS.

Deem, R. \& Brehony, K. (2000). Doctoral students' access to research cultures: Are some more unequal than others? Studies in Higher Education, 25(2), 149 -165.

de Kleijn, R. A. M., Mainhard, T., Meijer, P. C., Pilot, A., \& Brekelmans, M. (2011). Master's thesis supervision: Relations between perceptions of the supervisor-student relationship, final grade, perceived supervisor contribution to learning and student satisfaction. Studies in Higher Education, 37(8), 925-939.DOI:10. 1080/03075079.2011.556717

de Kleijn, R. A. M., Meijer, P. C., Pilot, A., \& Brekelmans, M. (2014). The relation between feedback perceptions and the supervisor-student relationship in master's thesis projects. Teaching in Higher Education, 19(4), 336-349. DOI: $10.1080 / 13562517.2013 .860109$.

Delamont, S., Parry, O., \& Atkinson, P. (1998). Creating a delicate balance: The doctoral supervisor's dilemmas. Teaching in Higher Education, 3(2), 157-172. DOI: 10.1080/1356215980030203.

Dysthe, O., Samara, A., \& Westrheim, K. (2006). Multivoiced supervision of Master's students: A case study of alternative supervision practices in higher education. Studies in Higher Education 31(3), 299-318. DOI: 10.1080/03075070600680562.

Edge, J. (1992). Co-operative development. ELT Journal, 46(1), 62-70.

Edge, J. (2001). Action research. Washington, DC: TESOL.

Edge, J. (2002). Continuing cooperative development: A discourse framework for individuals as colleagues. Ann Arbor: University of Michigan Press.

Edge, J. (2006). Computer-mediated cooperative development: Non-judgmental discourse in online environments. Language Teaching Research, 10(2), 205-227.

Garcia, M. E., Malott, R. W., \& Brethover, D. (1988). A system of thesis and dissertation supervision: Helping graduate students succeed. Teaching of Psychology, 15(4), 186-191. DOI: 10.1207/s15328023top1504_2. 
Gatfield, T. (2005). An Investigation into PhD supervisory management styles: Development of a dynamic conceptual model and its managerial implications. Journal of Higher Education Policy and Management, 27(3), 311-325. DOI: $10.1080 / 13600800500283585$

Lee, A., \& Green, B. (Eds.) (1998). Postgraduate studies, postgraduate pedagogy. Sydney: Centre for Language and Literacy.

Lindén, J. (1999). The contribution of narrative to the process of supervising $\mathrm{PhD}$ students. Studies in Higher Education, 24(3), 351-369. DOI: 10.1080/03075079912331379945.

Mercer, N. (1995). The guided construction of knowledge: Talk amongst teachers and learners. Clevedon: Multilingual Matters.

Sangani, H. R. (2009). How reflective practice impacts on English writing teachers in a particular context in Iran Unpublished PhD Thesis. University of Manchester, United Kingdom.

Sangani, H. R. (2012). Post-method and Muslim EL teachers. Paper presented at the First Conference on Language Learning \& Teaching: An Interdisciplinary Approach (LLT - IA). Mashhad: Ferdowsi University. Retrieved from http://confnews.um.ac.ir/images/41/conferences/llt/cd36.pdf

Sangani, H. R., \& Stelma, J. (2012). Reflective practice in developing world contexts: A general review of literatureand a specific consideration of an Iranian experience. Professional Development in Education, 38(1), 113-129.

Schön, D. A. (1983). The reflective practitioner: How professionals think in action. New York: Basic Books.

Schön, D. A. (1987). Educating the reflective practitioner: Toward a new design for teaching and learning in the professions. San Francisco: Jossey-Bass.

Sidhu, G. K., Kaur, S., Fook, C. Y., \& Yunus, F. W. (2014). Postgraduate supervision: Comparing student perspectives from Malaysia and the United Kingdom. Procedia: Social and Behavioral Sciences, 123, 151-159. DOI: 10.1016/j.sbspro.2014.01.1409

Styles, I., \& Radloff, A. (2001). The synergistic thesis: Student and supervisor perspectives. Journal of Further andHigher Education, 25(1), 97-106. DOI: 10.1080/03098770020030533

Yeatman, A. (1995). Making supervision relationships accountable: Graduate student logs. Australian Universities'Reviews, 2, 9-11.

Zuber-Skerritt, O., \& Ryan, Y. (1994). Quality in postgraduate education. London: Kogan Page. 